\title{
Contribuții la dezvoltarea pareneticii în cultura română veche
}

\author{
Drd. Mihaela BURCEA \\ Institutul de Istorie şi Teorie Literară „,G. Călinescu”, \\ Academia Română
}

\begin{abstract}
Résumé: La littérature parénétique a beaucoup influencé la pensée et les mentalités dans la culture ancienne roumaine, mais aussi le style de l'écriture moderne et contemporaine. Les débuts chez les roumains sont marqués par l'apparition de l'œuvre Invățăturile lui Neagoe Basarab către fiul său Teodosie jusqu'au moment quand l'ensemble de textes pédagogiques avait cessé d'exister dans l'espace byzantin. À travers ces enseignements et par la préférence pour ce modèle littéraire, la culture roumaine s'inscrit dans une tradition qui fait continuer le rôle pédagogique et politique des écritures byzantines. Il s'agit d'une réintégration d'archétypes littéraires, mais en même temps on a pu observer des aspects différents, spécifiques au monde roumain. Ces textes appartiennent à la catégorie Miroir des princes et apparaissent en Roumanie jusqu'à l'époque où les écrits occidentaux affirment leur intérêt. Il est intéressant d'observer l'évolution de la littérature parénétique dans le monde roumain, de voir ses influences, d'analyser les causes historiques, de mettre à discussions le monde byzantin et celui de l'Occident et de suivre les points communs, les différences et les préférences pour étudier cette tendance des enseignements dans la culture ancienne.
\end{abstract}

Mots clés: littérature parénétique, culture roumaine, archétypes littéraires, byzantin, Occident.

Neagoe Basarab deţine, în literatura noastră veche, locul lui Eminescu în literatura
modernă : este expresia integrală, la o înălţime neatinsă de niciun alt creator, a
profilului moral şi a valorilor intelectuale ale poporului român întreg

(Zamfirescu, 1969 : 113)

Literatura parenetica a lumii vechi româneşti a fost, pe cât de îndelung dezbătută, pe atât de inedit necesară în conturarea unui model literar, care să surprindă note şi aspecte creionate în ideea unei nişe alteritare, ce probează cauzele unui istorism tensionat şi influenţele ce țin de un mecanism literar al genurilor - şi pe cât de interesant, al spiritualităţii şi sensibilităţii. Prin acestea, parenezele din literatura română pot fi considerate un liant între învățăturile 
bizantinilor şi cele ce vor conduce la schiţarea modelului occidental, asemănându-se şi detaşându-se în acelaşi timp de tot ceea ce însemna canon literar în acele vremuri. Încărcate cu o sensibilitate aparte, învăţăturile...acestea cu parfum de ceară topită din lumânări aprinse într-o modestă biserică valahă şi cu înţelepciuni vechi (...) plac enorm la lectură, ne întorc în timp şi ne sugerează reveriile unei lumi vechi ce îşi caută, în nestatorniciile, blestemăţiile şi spaimele istoriei, un model de existență bazat pe ideea de perfecțiune şi întregire a spiritului. (Simion, 2017 :

6)

Dacă în mediul bizantin, cuvintele de înțelepciune adresate iniţial împăraţilor şi fiilor de împăraţi formează apetenţa pentru acest stil de scriere, mai târziu, acesta se va dezvolta, chiar şi după o perioadă însemnată de timp. Este binecunoscut faptul că grecii sunt printre primii care au scris versuri şi proză în care sunt incluse învăţături pe care mai apoi bizantinii le-au preluat. Astfel, Synesios din Cirene (cca 370 - cca 412) este recunoscut pentru discursul său numit Despre împărăție, pe care i-l adresează împăratului Arcadius, fiul lui Theodosie I cel Mare. Pentru reuşita sa, el ține să îi amintească pe Platon, Aristotel şi Dion Hrisostomul.

Diaconul Agapet este renumit pentru că alcătuieşte Sfaturi-le pentru impăratul Justinian ale căror principii sunt preluate din cuvântările lui Isocrate (436-338), adresate lui Nikokles şi Evagoras, şi ale căror idei vor alcătui şi capitolele scrise de patriarhul Fotie, atribuite împăratului Vasile I Macedoneanul (867-886). Cum s-a observat, în fruntea celor 72 de "capete" alcătuite, împăratul este sfătuit să-l cinstească pe Dumnezeu şi să-i învețe pe supuşi dreptatea: cinsteşte, împărate, mai presus de toate, pe Acela care de această cinstire te-a învrednicit, pe Dumnezeu, căci după chipul împărăţiei Lui cereşti e întocmirea stăpânirii tale pământeşti, cu schiptrul domniei te-a dăruit ca pe oameni păzirea dreptății să-i înveți (http://www.romaniaregala.ro/atitudini/nicolaeserban-tanasoca-2/).

Învăţăturile diaconului Agapet comportă caracteristici pe care le regăsim şi în cele formulate, cu mult timp mai târziu în cultura română veche, de Neagoe Basarab pentru moştenitorul său, Theodosie. Astfel, se observă faptul că printre preocupările împăratului trebuie să se regăsească grija faţă de săraci, sentimentul de omenie faţă supuşii săi (8....dă ascultare celor împresuraţi de sărăcie....16....trebuie, aşadar, de la unii să luăm, celorlalţi să le dăm, şi inegalitatea s-o prefacem in egalitate......20Vrednică pe bună dreptate de cinstire este împărăția noastră, pentru că față de duşmani îşi arată tăria, faţă de supuşi omenia.....23Poartă-te cu slujitorii tăi tot aşa cum te rogi să se poarte Domnul cu tine...Să dăm, aşadar, arvună de milă celui milostiv.....35 ...Cei supuşi împotriva voinţei lor, găsesc oricând 
prilej să se răzvrătească, dar cei ce s-au supus din a lor voință au față de stăpânire statornică bunăcredință), dar şi respectarea legilor (27Sileşte-te tu însuţi să respecți legile, de vreme ce nimeni de pe pământ nu poate să te silească).

Din filosofia antică, se inspiră şi Teophylact Hephaistos, arhiepiscopul Ohridei (1090-1108) ce scrie o lucrare parenetică în care îi face recomandări legate de moralitate şi justiţie lui Constantin Porfirogenetul şi în care îi citează pe Platon, Dion Hrisostomul, Xenofon, Polybius, Themystios şi Synesios. Aceasta a apărut într-o primă ediție greco-latină Patris nostri Theophylacti arhiepiscopi Bulgariae Institutio regia od Porphyrogenitum Constantinum, în 1651 la Paris.

Vasile I Macedoneanul (867-886) dedică cele şaizeci şi şase de capitole îndrumătoare preaiubitului său fiu, alcătuind lucrarea parenetică Învăţăturile către fiul său, Leon cel Înţelept. Există ipoteza potrivit căreia această scriere ar aparține savantului Fotie, patriarh al Constantinopolului. Dacă primele două capitole ale cărții îl învață pe viitorul împărat despre educație şi credinţă, în capitolul al X-lea, împărăția este comparată cu o comoară ce trebuie păzită şi condusă prin virtute: Virtutea este cea mai importantă în stat. Dacă, prin demnitatea ta, stăpâneşti peste mulţi oameni, iar după virtute eşti mai mic decat alţii, atunci nu eşti cel mai bun împărat, ci vei fi condus de ceilalți oameni care sunt mai virtuoşi. (Învăţăturile Impăratului Vasile I Macedoneanul către fiul său, Leon cel Înţelept, 2010 : 24).

Împăratul este sfătuit şi să păstreze împărăţia nevătămată şi să devină un exemplu pentru supuşii săi prin săvârşirea dreptăţii, să nu lase cale liberă celor ce vor să facă nedreptăți, să-l ajute pe cel nedreptăţit, făcându-i dreptate, iar pec el ce nedreptățeşte să îl pedepsească: Dacă vei avea faptele în conformitate cu ceea ce spui, pe oamenii care îţi judecă faptele îi vei avea martori de netăgăduit şi următori întru totul ai desăvârşirii tale. (Învăţăturile Împăratului Vasile I Macedoneanul către fiul său, Leon cel Înţelept, 2010 : 34), dar şi să facă milostenie săracilor, să îi ajute şi să îi răsplătească pe cei ce se jertfesc pentru binele poporului, explicându-i că cei care sunt înzestrați cu virtutea milosteniei, au de câştigat sufleteşte şi trupeşte şi că bogăția nu poate convieţui cu virtutea: Dobândeşte, aşadar, obiceiul să faci milostenie, ca şi tu să dobândeşti mila lui Dumnezeu. (Învățăturile Impăratului Vasile I Macedoneanul către fiul său, Leon cel Inţelept, $2010: 46$ )

Constantin VII Porfirogenetul (905-959), fiul lui Leon al VI-lea cel Înțelept, cunoscut şi ca “împăratul născut în purpură”, scrie mai multe opere bizantine cu scopul de a oferi fiului său Romanos un manual de învătături, un îndreptar pentru a conduce imperiul ce se întindea din Asia până în Dalmația, 
de la Herson până în bazinul oriental al Mediteranei. Alcătuieşte între anii 934944 De thematibus, în care prezintă provinciile Imperiului bizantin, dar şi De ceremoniis aulae Bizantinae, un tratat cu privire la ceremonialul practicat la curtea imperială din Bizanţ.

Lucrarea parenetică, Carte de învăţătură pentru fiul său Romanos, iniţial numită De administrando imperio, poate fi considerată un veritabil excurs în istoria popoarelor şi este cunoscută îndeosebi pentru rolul său didactic, de a-i oferi învăţături în conducerea imperiului fiului său, Romanos (959-963). Mărturisind încă din primul capitol al cărții sale, care este scopul urmărit, autorul se foloseşte de cuvinte clare, simple şi spuse repetat, asemenea unui curs de apă pe un loc şes şi neted (Porfirogenetul, 1971 : 14) pentru a-i arăta fiului său ce deosebiri există între popoare şi cum trebuie să se comporte faţă de ele. Acesta îi oferă fiului său învăţături ce pot să-i aducă pricepere în guvernare şi care se bazează pe atenţia faţă de supuşii săi: Ascultă aşadar, fiule, ce cred ca tu să ştii numaidecât şi să ții bine minte, ca să poți guverna țara cu succes. Căci spun că şi pentru toți ceilalţi dintre supuşi învăţătura e un bine, dar mai ales pentru tine, care eşti indatorat să ai grijă ca tuturor să le meargă bine, şi ca să porți cîrma lumii întregi şi să o guvernezi. (Porfirogenetul, 1971 : 14).

Manuel al II-lea Paleologul (1391-1425), împărat şi teolog ortodox, este autorul operei Sfaturi pentru educația împărătească, scriere parenetică adresată fiului său, împăratul Ioan al VIII-lea Paleologul (1425-1448), despre care cercetătorii afirmă că ar fi fost alcătuită în perioada 1406-1417 şi tipărită pentru prima dată în 1578. Nicolae Şerban Tanaşoca o consideră "cea din urmă capodoperă a literaturii zise bazilicale.Textul a fost tipărit pentru prima oară la Basel, în 1578, într-o ediție greco-latină, reprodusă în varianta românească de Simona Nicolae, văzându-1 ca “o chintesenţă a întregii literaturi parenetice".Cartea cuprinde 100 de capitole (sau oglinzi), în prefaţă fiind cuprinse reflecţii şi sfaturi printr-o "Scrisoare de început al capetelor rânduite". Cercetătorii cad de acord că lucrarea a fost compusă între anii 1406-1417.

Începuturile literaturii parenetice la români sunt marcate prin apariţia operei Invăţăturile lui Neagoe Basarab către fiul său Theodosie, chiar în momentul în care ansamblul impresionant de texte pedagogice încetase a fiinţa cu câteva decenii înainte în literatura bizantină.

Prin aceste învătături, nu doar că se produce un eveniment al reînnodării tradiţiei literare, mai cu seamă în spaţiul cultural sud-est european, ci ele fac gestul unei revitalizări a genului, înscriind în acest continuum al literarităţii caracteristici ce diferenţiază etosul, construind un stil şi impunând o manieră în cultura veche românească, prin preferința pentru categoria de texte cunoscută 
drept "oglinda principeluï("Furstenspiegel”, "Miroir des princes", "Speculum regale"). Despre efortul de reconstituire a acestui sistem de modele parenetice, Dan Horia Mazilu afirma că acesta a fost întreprins de năzuințele şi nevoile lăuntrice ale literaturii române, de starea configurată de gustul, sensibilitatea şi mentalitatea lumii româneşti care punea la cale primele operaţii de deschidere.

Cât despre această istorie a dobândirii ideii de spiritualitate şi a mentalității legate de modul în care un principe dobândeşte virtutea prin dragostea faţă de Dumnezeu, judecata dreapta şi grija faţă de supuşi, acestea se oglindesc şi în preocupările criticilor de seamă, pe coperta a IV-a a celui dintâi volum din Literatura română veche, ediție îngrijită de G.Mihăilă şi Dan Zamfirescu, aflându-se înscrisă afirmaţia următoare, ce îi aparţine lui G.Călinescu: Cultura veche este un (...) bloc (de marmură)în care stau încă nenăscuți Eminescu şi Creangă, Caragiale şi Sadoveanu. A descifra prezenţa lor virtuală în acea materie simplă, privind din prezent spre origini, aceasta e marea misiune a unui adevărat istoric.

După cum se cunoaşte, textul învăţăturilor a fost scris în limba slavonă între 1517 şi 1521, versiunea originală păstrându-se într-un singur manuscris şi aşa cum o arată filigranele hârtiei, acesta a fost datat aparţinând aceleiaşi perioade în care a trăit Neagoe Basarab. Nu se ştie nici astăzi modul în care manuscrisul a ajuns în posesia Bibliotecii Naţionale din Sofia, însă mai întâi cele 98 de file cunoscute iniţial au fost editate de slavistul rus P.A.Lavrov şi reproduse în versiunea românească de P.P. Panaitescu în "Cronicile slavoromâne din sec. XV-XVI şi publicate de Ioan Bogdan. Mai târziu, G.Mihăilă a mai descoperit 13 file în manuscrisul de la Sofia, pe care le-a publicat în "Romanoslavica", XIV, 1967.

S-a constatat că opera voievodului român se aseamănă prin sursele şi izvoarele bizantine şi nu se aseamănă totodată, învăţăturile acestea aducând ca element de noutate în memoria culturală o atitudine ce ține mai degrabă de estetica unei spiritualităţi şi sensibilități ce învederează specificul domniilor din cultura română. În tot textul învăţăturilor, se observă această preocupare continuă față de grija față de Dumnezeu: Iubitu mieu fiiu, mai nainte de toate să cade să cinsteşti şi să lauzi neîncetat pre Dumnezeu cel mare şi bun şi milostiv şi ziditorul nostru cel înţelept, şi zioa şi noaptea şi în tot ceasul şi în tot locul. (Basarab, $2001: 21)$.

Considerată un manual, opera se adresează moştenitorului tronului care trebuie să se preocupe permanent de păstrarea şi transmiterea acestor învăţături ca un "uns al lui Dumnezeu“. De exemplu, partea a doua prezintă grija pe care trebuie să o aibă un conducător pentru cinstirea icoanelor: Fătul mieu Theodosie şi 
voao cinstiţilor şi dulcilor miei domni, care veți fi în urma noastră domni şi biruitori ţărâi aceştiia, aşijderea şi dumneavoastră, iubiții mei boiari, aşa vă învăţ: întâiu să cinstiţi cinstitele şi sfintele icoane pentru că icoanele cu adevărat sunt semnul şi chipul Domnului nostru Iisus Hristos şi pecétea lui. (Basarab, 2001 :130)

În aceeaşi idee a dobândirii virtuţii prin iubirea faţă de Dumnezeu, în partea dedicată spunerii şi încredinţării pentru frica şi dragostea lui Dumnezeu, se menţionează: neîncetat faceți voia lui Dumnezeu şi iubiţi dreptatea lui (...) Că rădăcina bunătăţilor iasti dulceaţa lui Dumnezeu. (Basarab, 2001 : 146) sau Întâi să aibi credință, dragoste şi nădéjde cătră Dumnezeu, că dragostea iaste mai mare dee toate. (Basarab, 2001 : 171).

Drept condiție pentru ca domnitorul să dobândească dragostea lui Dumnezeu şi să se mântuiască este menționată judecata dreaptă: Fătul mieu, judecata 2 lucruri are: unul spre pagubă, iar altul spre uşurare şi spre izbândă. Iar domnul carele va judeca pre dreptu, acela-i domn adevărat şi unsul lui Dumnezeu şi va dobândi şi lumina care nu va tréce niciodată. (Basarab, 2001 : 208)

O altă caracteristică pe care trebuie să o dobândească domnitorul este milostenia față de săraci, calitate comparată cu bunătatea faţă de supuşii de la curtea domnească: Cade-să domnului să miluiască pre săraci, iar nici pre slugile tale să nu le laşi, nici să le uiți, ci mai vârtos să-ți miluieşti slugile decât pre săraci. (Basarab, 2001 : 215) sau Şi iată că te învăts şi te sfătuescu şi de aceasta, iar tu să te apropii cătră sfatul mieu şi să-l asculţi: tuturor să împarţi milostenie, ca să fii şi tu miluit de fața Domnului nostru Iisus Hristos.(Basarab, 2001 : 216)

Şi în Sfaturile către Alexandru Iliaş, date de Matei al Mirelor, se găsesc învățături privitoare la cum se cade ca domnii să aibă teamă de Dumnezeu şi să fie buni judecători aşa cum reiese din secvența: temerea de Ddieŭ e inceputulŭ intieleptiune $\breve{~ s ̧ i ~ t e m e l i a ~ j u d e c a ̂ t i l o r u ̆ ~ d r e p t e ; ~ s i ~ c i n e ~ a ~ c a ̆ u t a t u ̆ ~ s a ̆ ~ c a p e t e ~ t e m e r e a ~ d e ~}$ Ddieŭ, s'a măntuitŭ de féra cea nevĕdiută, de mórte (Tesauru de monumente istorice, $1862: 45)$.

Ca şi în Învăţăturile lui Neagoe Basarab către fiul său Theodosie, sunt inserate exemple ce demonstrează că strălucirea unei domnii şi reuşita în conducere se datorează iubirii de Dumnezeu şi judecăţii drepte. Un domnitor va fi temut şi respectat deopotrivă de supuşi cât timp va face judecată dreaptă: Iea dară bine

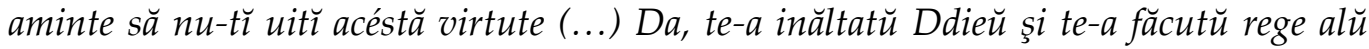
tuturora, ca tot $\breve{~ s a ̆ ~ s e ~ t e ́ m a ̆ ~ d e ~ t i n e ; ~ d a r a ̆ ~ s i ~ t u ~ s e ~ c a d e ~ s a ̆ ~ f i u ̆ ~ f a ̂ r a ̆ ~ m a ̂ n d r i a ̆ ~ s i ~ d r e p t u ~}$ judecătoriŭ, judecând $\breve{u}$ după adevêrŭ si dreptate. (Tesauru de monumente istorice, $1862: 46$ )

Tot textul este alcătuit din sfaturi formulate pe baza a "ce se cade domnilor"şi a"ce nu se cade", pentru a guverna bine trebuind să asculte de 
părerea consiliului, să fie în pace cu vecinii lor, să se asigure de paza hotarelor ţării sau să onoreze sărbătorile şi să meargă la biserică, să fie milostivi şi iubitori de săraci (Nu e virtute ca milostivirea; ea stâ asìa aprópe de Ddieŭ ca si preotìa. Fericitŭ omulŭ ce a căstigat'o !) În schimb, nu se cade domnilor să-şi încalce jurământul, fiindcă odată făcut acesta nu mai poate fi rupt, să nu îşi respecte

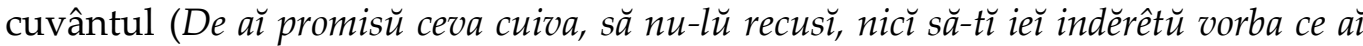
vorbitŭ (...) Cuvêntulŭ unuı̆ domnitoriŭ e pétră nestimată, si togmai ca si dênsa se cade

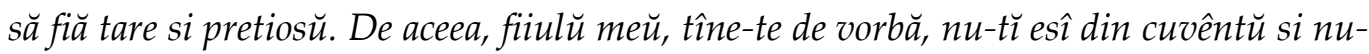

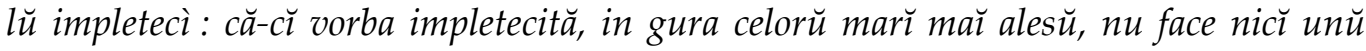
banŭ si n'are nič unŭ pretiŭ. (Tesauru de monumente istorice, 1862 :), să îşi anuleze semnătura şi sigiliul lor,nu se cade să fie mândri, ci li se recomandă să ţină o dreaptă măsură în purtarea lor, nu se cade a defăima omul bisericii, să bea vin mult sau să fie bețivi.

Opera parenetică Sfătuiri creştino-politice a lui Antim Ivireanul cuprinde sfaturi adresate domnitorului Țării Valahiei, Ioan Ştefan Cantacuzino. Fiind culese din mai multe cărţi şi împrumutând idei din filosofia antică, ele se subsumează unui singur scop, acela de a îndemna la piositate, religiositate şi moralitate pe Domnitorul țărĕ̌. (Ivireanul, 1890: din prefaţă). Primele stihuri notate pe prima pagină dezvăluie cele trei semne ale măreției domnitorului: Cele

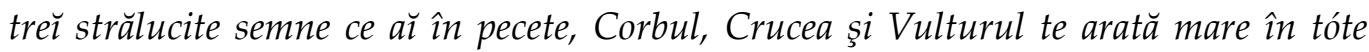

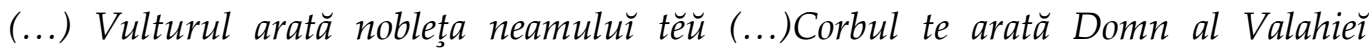
(...)Crucea te mărturiseşte apărător respectat al Bisericeı̆ lŭ Christos...(Ivireanul, $1890: 5)$

Aşa cum mărturiseşte în introducere însuşi autorul, din dragostea pe care domnitorul o arată ca să guverneze nejignit şi plăcut lui Dumnezeu (Ivireanul, 1890 : 6), el alcătuieşte o Antologie de sentință din diferite cărţi de sentinţă: le-am expus în stihurŭ simple politiceştŭ ritmice (...) fiind-că scopul meŭ a fost cu totul ca să le

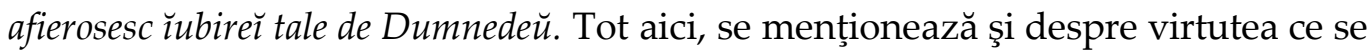
obţine prin învăţătură: Virtutea este fórte bună, dar bună este şi ştiinţa, acestea înalţă prin învĕțătură şi dau o reputație frumósă. (Ivireanul, 1890 : 10); Dacă te sfătueşt ̌ cu

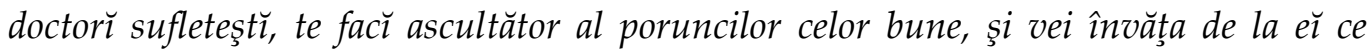

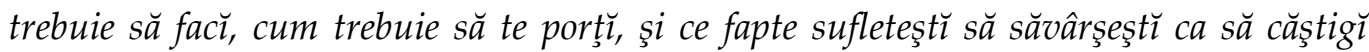
viaţa vecĭnică. Virtutea o fiule !este liniştea sufletului, cuviința Domnitorului şi a tuturor celor ce se mântuesc (Ivireanul, 1890 : 12).

La începutul veacului al XVIII-lea (aproximativ 1709), Nicolae Costin traduce Ceasornicul domnilor după Libro aureo del gran emperador Marco Aurelio con el Relox de Principes, opera lui Antonio de Guevara, tipărită într-o ediție definitivă în 1529, în Spania, având drept model traducerea în limba latină a 
germanului Johann Wankelius (în traducerea latină, titlul a fost inversat, punându-se accentul pe Ceasornic - Horologium Principum sive de vita M.Aurelii).

Despre legătura lui Nicolae Costin cu Nicolae Mavrocordat s-a tot discutat, întrucât acesta, fiind mare logofăt în divanul lui Mavrocordat, a scris cronica oficială a domniei lui. Este binecunoscut faptul că în biblioteca lui Constantin Mavrocordat, tatăl lui Nicolae Mavrocordat, se afla opera Institutione del Principe christiano per Mambrino Roseo, traducere prescurtată, în fapt, a Ceasornicului domnilor - fără a include cadrul istoric şi scrisorile lui Marcu Aureliu - lucru ce i-a permis lui Nicolae Mavrocordat să cunoască această operă

Dacă prima parte a operei originale este dedicată vieții lui Marcu Aureliu, cea de-a doua se constituie într-un ceasornic al vieții, prezentând normele după care trebuie să se ghideze un principe pentru a fi un bun creştin, pentru a avea o viaţă de familie împlinită şi a reprezenta un model pentru supuşii săi. De aceea, Guevara îi pune titlul de Relox de Principes, iar Nicolae Costin îi traduce titlul în Ceasornicul domnilor.

Cât despre apariția operelor parenetice în spaţiul occidental, se cunoaşte faptul că ele sunt contemporane cu Invățăturile lui Neagoe Basarab către fiul său Theodosie, dar şi că expun problema dobândirii puterii, diferit faţă de modelele bizantine.

Erasmus din Rotterdam (pe numele adevărat Geert Geertz) scrie Panegiricul pentru Filip (1504) în care îl prezintă pe Filip cel Frumos, arhiducele de Austria, tatăl lui Carol Quintul, dar şi Educarea principelui creştin (1516), în care realizează un portret al principelui în viziunea umanistă, văzut ca principele-filozof, reordonând virtuţile şi primejdiile morale ce-l pândesc pe acesta.

Tot în secolul al XVI-lea, opera lui Niccolò Machiavelli, compusă în 1513, tipărită în 1532, îl prezintă pe ducele Valentino, fiul papei Alexandru al VI-lea, ca model al principelui perfect. $\mathrm{Cu}$ toate acestea, principiile criteriului desavârşirii sunt diferite faţă de cele din mediul bizantin, şi chiar românesc, fiindcă se prezintă modalităţile prin care se dobândeşte puterea în țara cucerită.

O altă operă despre pregătirea, comportamentul şi cultivarea însuşirilor pe care trebuie să le aibă un curtezan perfect este Curteanul lui Baldesar Castiglione, scrisă între 1508 şi 1516, dar tipărită în 1528 la Veneţia. De vreme ce cartea reprezintă un cod moral şi estetic din epoca Renaşterii, despre pregătirea curtezanului se discută în casa ducelui Urbino, mai ales despre modul în care se comportă faţă de femei, cum se îmbracă şi care sunt însuşirile pe care trebuie să le aibă în societate. 


\section{BIBLIOGRAFIE}

Basarab, Neagoe, 2001: Invăţăturile lui Neagoe Basarab către fiul său Theodosie, Bucureşti-Chişinău, Editura Litera Internaţional.

Ivireanul, Antim, 1890 : Sfătuiri creştine-politice. Cătră Prea piosul şi Prea Inălţatul Domn şi Egemon a tótă Ungro-Vlahia, Domnul Domn Ioan Ştefan Cantacuzin Voevod, Bucureşti, Tipografia Cărţilor Bisericeşti.

Invăţăturile Impăratului Vasile I Macedoneanul către fiul său, Leon cel Înţelept în Conducătorul creştin înţelept, 2010: Bucureşti, Editura Basilica a Patriarhiei Române.

Porfirogenetul, Constantin, 1971: Carte de învăţătură pentru fiul său Romanos, Bucureşti, Editura Academiei Republicii Socialiste România.

Simion, Eugen, 2017 : Caiete critice, nr.11, Fundaţia Naţională pentru Ştiinţă şi Artă.

Zamfirescu, Dan, 1969: Literatura română veche, volumul I, Bucureşti, Editura Tineretului.

Tesauru de monumente istorice, 1862 : Bucureşti, Tipografia Naţională a lui Stefanu Bassidescu. 